\section{Tulip-bundle technique as rescue hemostatic therapy in a deep Mallory-Weiss tear}

An 80-year-old woman who was anticoagulated with rivaroxaban for a previous deep venous thrombosis of the left lower limb presented with a 12-hour history of hematemesis. Her physical examination was unremarkable, and she had a blood pressure of $153 / 78 \mathrm{mmHg}$ and heart rate of 75 beats/minute. Laboratory test results showed a hemoglobin level of $13.1 \mathrm{~g} / \mathrm{dL}$. Upper gastrointestinal endoscopy revealed a deep Mallory-Weiss tear with a visible vessel and active pulsatile bleeding located in a hiatus hernia ( $\bullet$ Fig. 1 a).

Because she was anticoagulated with rivaroxaban, mechanical hemostasis with clips (Resolution Clip; Boston Scientific) was selected as the treatment ( $\bullet$ Fig. 1 b) but despite the application of six hemostatic clips, bleeding persisted ( $\bullet$ Fig. 1 c). Subsequently, a tulip-bundle technique was planned ( $\bullet$ Video 1 ). A detachable snare (MAJ-254; Olympus, Tokyo, Japan) was placed over the clips ( Fig. $1 \mathrm{~d}$ ), which resulted in immediate hemostasis $(\bullet$ Fig. 1e). Adjunctive management with nil per os, a proton pump inhibitor as a continuous infusion, metoclopramide, and prophylactic enoxaparin instead of rivaroxaban was instituted. The patient remained asymptomatic and was discharged 3 days later.

Mallory-Weiss syndrome accounts for $6 \%-14 \%$ of all cases of upper gastrointestinal bleeding, mainly occurring at the gastroesophageal junction or gastric cardia [1].

The tulip-bundle technique consists of the placement and tightening of a detachable snare around clips [2]. This technique has a range of applications, including hemostasis and closure of perforations and fistulae $[2,3]$. Moreover, this technique may represent an effective rescue treatment in bleeding that is refractory to initial hemostasis in patients with comorbidities that limit hemostatic options, as highlighted in this report.

\section{Competing interests: None}

\section{Ana Ponte, Rolando Pinho, Joana Silva, Jaime Rodrigues, João Carvalho}

Department of Gastroenterology, Centro Hospitalar Vila Nova de Gaia, Espinho, Portugal

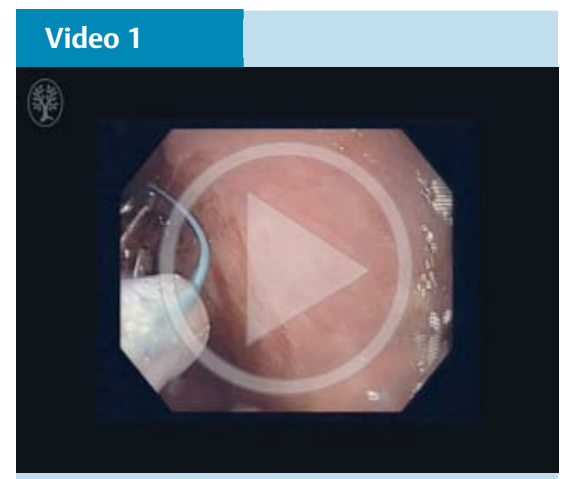

Endoscopic views showing the tulip-bundle technique as rescue treatment for a MalloryWeiss tear with persistent bleeding despite proper application of several hemostatic clips. The placement of an endoloop around the clips results in the achievement of definitive hemostasis.
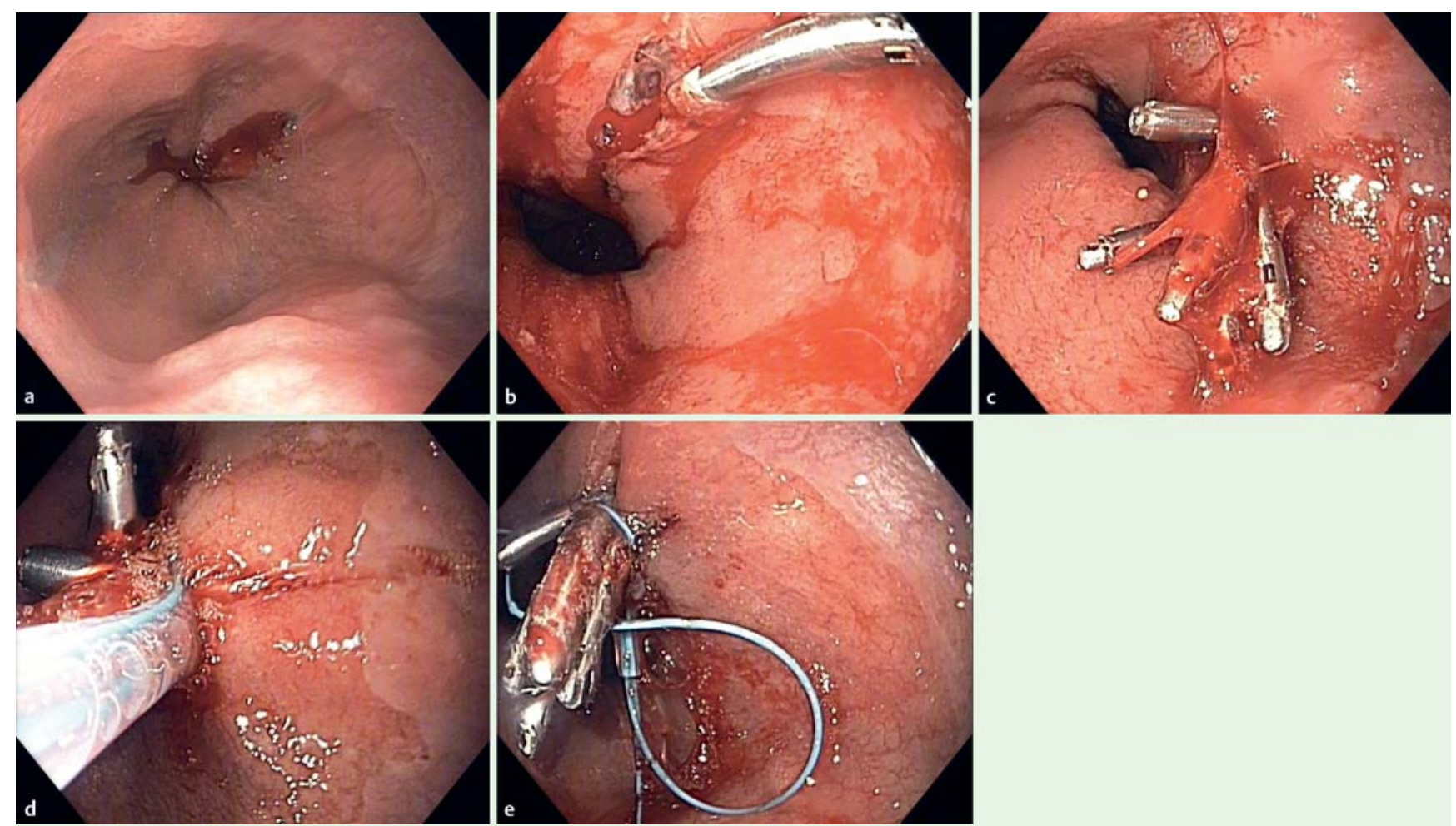

Fig. 1 Endoscopic views showing: a a Mallory-Weiss tear with active bleeding located in a hiatus hernia; $\mathbf{b}$ placement of a hemostatic clip; $\mathbf{c}$ persistent bleeding after the placement of six hemostatic clips; $\mathbf{d}$ a detachable snare tightened around the hemostatic clips; e cessation of the bleeding after completion of the tulip-bundle technique. 


\section{References}

1 Kim IJ, Sheibani S, Park $S$ et al. Causes of bleeding and outcomes in patients hospitalized with upper gastrointestinal bleeding. J Clin Gastroenterol 2014; 48: 113-118

2 Pinho R, Silva J, Ponte A et al. Grasp-to-retract modification of the tulip-bundle technique in forward and retroflexed position for difficult hemostasis in the sigmoid colon. Endoscopy 2015; 47 (Suppl. 01): E554 - E555

3 Perri F, Gentile M, Scimeca D et al. Closure of a gastrocutaneous fistula by a tulip-bundle technique. Endoscopy 2011; 43 (Suppl. 02): E419

\section{Bibliography}

DOI http://dx.doi.org/

10.1055/s-0042-100200

Endoscopy 2016; 48: E42-E43

(c) Georg Thieme Verlag KG

Stuttgart · New York

ISSN 0013-726X
Corresponding author

Ana Ponte, MD

Department of Gastroenterology Centro Hospitalar Vila Nova de Gaia Rua Conceição Fernandes 4434-502 Vila Nova Gaia Portugal

Fax: +351-227-868369

ana.ilponte@gmail.com 